\title{
Isothermal Pneumatc Molding of Dome-Shaped Parts of Anisotropic Material in Short-Time Creeping Mode
}

\author{
Sergey Sergeevich Yakovlev ${ }^{1}$, Sergey Nikolaevich Larin ${ }^{1} \&$ Valeriy Ivanovich Platonov ${ }^{1}$ \\ ${ }^{1}$ Tula state university, Tula, Russian Federation \\ Correspondence: Sergey Nikolaevich Larin, Tula state university, Tula, Russian Federation.
}

Received: October 16, 2014 Accepted: November 1, 2014 Online Published: June 29, 2015

doi:10.5539/mas.v9n8p13 URL: http://dx.doi.org/10.5539/mas.v9n8p13

\begin{abstract}
Studying isothermal straining of dome-shaped shells with the aim of evaluating kinematics of the material flow, stress and strained conditions, force conditions, geometrical dimensions of shells and possibility frontier of straining. The theoretical study of the isothermal straining processes has been performed on the basis of the theory of short-time creeping of anisotropic material. There has been revealed the influence of technological parameters, conditions of loading, and geometry of working tools on the kinematics of material flow produced by friction conditions on the blank and tool contact surfaces, stress and strain states, force conditions, possibility frontiers of form-shaping of operations of isothermal deforming of dome-shaped shells made out of high-strength anisotropic materials. Conclusions. The equations obtained can be used for theoretical analysis of operations of isothermal straining of dome-shaped shells in the mode of short-time creeping.
\end{abstract}

Keywords: anisotropy, dome-shaped shells, high-strength materials, stress, strain, isothermal straining, viscosity, damaging, destruction

\section{Introduction}

Dome-shaped parts have found their wide usage in various industries. The traditional methods of their production by means of pressing are rather labor-consuming and problematic for securing requisite geometric precision, due to residual stress, which causes deformation of the contour and hence an extensive scope of fitting and component-adjusting operations to adjust the parts to the requisite dimensions.Residual stress is largely caused by the inbuilt anisotropy of the mechanical properties in the sheet under deformation and by the uneven character of the deformations. Isothermal changing of the shape of dome-shaped parts with gas of highly strong aluminum and titan alloys is considerably advantageous versus the conventional processing methods, and is quite promising for industrial use [1-6].

Sheet material, subjected to deforming processes, as a rule, possesses certain anisotropy of mechanical properties, determined by the material grade, by technological modes of its production, which can produce a positive or a negative effect upon stable procedure of technological processes of metal treatment by pressure under various temperature-speed modes of deformation [5-15].

Single- and multilayered cellular structures (waffle-grid structure) are used for the shells of the product vessels. At a high load-bearing capacity, these structures possess relatively light weight and strength balance while loading. The existing technological processes of manufacturing cellular structures include machining operations (milling) and electroerosion. Technological principles of a hot slow-speed forming through the excess gas pressure can be used in the production of cellular structures out of aluminum and titanium alloys.

\section{Methodology}

The theoretical study of processes of isothermal straining is carried out on the basis of the theory of short-time creeping of anisotropic material. The object of study was stressing of an anisotropic material under conditions of short-time creeping. Short-time creeping shall be assumed as a slow straining under conditions of viscous or ductile flow. The elastic components of strain are ignored [1]. The analysis of the stress and strain conditions of the blank, of the force conditions of isothermal pneumatic molding of dome-shaped parts has been performed numerically by the method of finite-difference mutual relations, use being made of computers, for joint solution of differential balance equations, equations of state and kinematic correlations under postulated initial and boundary conditions [10]. The possibility frontiers of deforming have been set on the basis of use of 
phenomenological criteria of destruction (stress and strain) of anisotropic material associated with accumulation of microdamages.

Main part. We have considered straining of a round sheet blank with radius $R_{0}$ and thickness $h_{0}$ by free bulging in the mode of viscous flow of material when exposed to the excess gas pressure $p=p_{0}+a_{p} t^{n_{p}}$ into a spherical matrix (Fig. 1). Here $p_{0}, a_{p}, n_{p}$ are stressing constants.

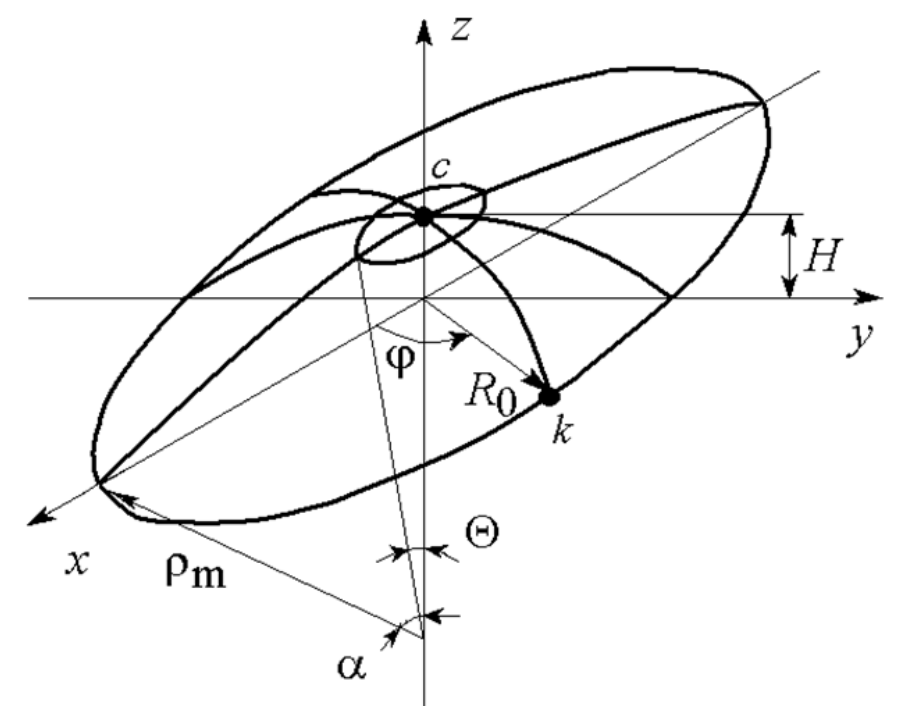

Figure 1. Scheme to the calculation of strained state of the blank middle surface in the meridian plane

The blank is fixed along the outer contour. The blank material is taken as transversally isotropic with anisotropy factor $R$; the stressed state of the shell is two-dimensional, i.e., the stress perpendicular to the sheet plane equals zero $\left([\operatorname{sigma}]_{z}=0\right)$. We consider stressing in the meridian plane of the shell as a membrane. Due to the symmetry of the mechanical properties of the material versus the blank axis, and due to the nature of the external forces behavior, stresses and velocities of straining, which are meridian, circumferential and normal to the median surface of the blank, are the chief ones.

The median surface of the blank remains a part of the spherical surface at every stage of the straining. A radial flow of material relative to the new center at every stage of the straining takes place at any meridian section of the shell.

According to the adopted allowances, the curvature radii of the meridian section $[\text { rho }]_{m}$ of the median surface, and those of the shell section by the conical surface perpendicular to the meridian arch, [rho $]_{t}$ are equal, i.e.,

$$
\rho_{m}=\rho_{t}=\rho=\frac{H^{2}+R_{0}^{2}}{2 H}
$$

where $H$ - is the height of the dome at the given time instant of straining.

It is assumed that the stresses are distributed evenly over the thickness of the element cut out of the membrane by meridian and conical surfaces in the vicinity of the point under consideration. As distinct from the available solutions, we make no limitation as to changing the thickness of the shell along the circumference arch in the meridian section.

The straining velocities in the meridian $[\mathrm{ksi}]_{m}^{c}$, circumferential direction $[\mathrm{ksi}]_{t}^{c}$ and along the thickness $[\mathrm{ksi}]_{z}^{c}$ of the shell are determined accordingly by the following formulas

$$
\xi_{m}^{c}=\left(\frac{\sin \theta}{\theta \sin \alpha}-\operatorname{ctg} \alpha\right) \dot{\alpha} ; \quad \xi_{t}^{c}=\left(\frac{\cos \theta}{\sin \alpha}-\operatorname{ctg} \alpha\right) \dot{\alpha} ; \quad \xi_{z}^{c}=\frac{\dot{h}}{h}
$$

Here [teta] - is the actual angle between the blank vertical line of symmetry and the radius-vector determining the position of the point in the median surface section by a diagonal plane; $\dot{\alpha}=d \alpha / d t ; \dot{h}=d h / d t$

It was assumed for the shell strain that at every step of straining there takes place a radial flow of the median 
surface point in the meridian plane relative to the new center at time instant $t+d t$, i.e., in direction [teta] $+d[$ teta].

The shell thickness in the dome of the middle surface of the shell $([$ teta $]=0)$ is found by the following expression

$$
h=h_{0} /\left(1+\frac{H^{2}}{R_{0}^{2}}\right)^{2}
$$

Change of the shell thickness depending on straining time $t$ at the point of fixation ([teta=alfa]) is found by the formula

$$
h=h_{0} \frac{H}{R_{0}\left(1+\frac{H^{2}}{R_{0}^{2}}\right) \operatorname{arctg} \frac{H}{R_{0}}}
$$

The values of the meridian $[\text { sigma }]_{m}$ and tangential [sigma $]_{t}$ stresses in the process of deforming with $\left[\mathrm{rho}_{m}=\mathrm{rho}_{t}\right]$, are found by the formula [10]:

$$
\sigma_{m}=\sigma_{t}=\frac{p \rho}{2 h}
$$

The equivalent velocity of straining $[\mathrm{ksi}]_{e}^{c}$ and stress [sigma $]_{e}$ at the dome apex (point "c") and at the fixation point of the shell in the contour (point "k") are calculated for anisotropic material respectively after formulas [5, 6]:

$$
\begin{gathered}
\xi_{e c}^{c}=\frac{2}{\sqrt{3}} \sqrt{2+R} \xi_{m c}^{c} \\
\xi_{e c}^{c}=\frac{2}{\sqrt{3}} \sqrt{2+R} \xi_{m c}^{c} ; \quad \sigma_{e c}^{c}=\frac{\sqrt{3}}{2 \sqrt{2+R}} \sigma_{m c} ; \\
\xi_{e k}^{c}=\left\{\frac{2}{3} \frac{(2+R)(R+1)}{2 R+1}\right\}^{1 / 2} \xi_{m k} ; \quad \sigma_{e k}=\left\{\frac{3}{2} \frac{2 R+1}{(2+R)(R+1)}\right\}^{1 / 2} \sigma_{m k}
\end{gathered}
$$

There has been considered a slow isothermal straining of a shell made out of a material, for which work the equations of state for the energy theory of creeping and damaging [6]:

$$
\xi_{e}^{c}=B\left(\sigma_{e} / \sigma_{e_{0}}\right)^{n} /\left(1-\omega_{A}^{c}\right)^{m} ; \quad \dot{\omega}_{A}^{c}=\sigma_{e} \xi_{e}^{c} / A_{n p}^{c},
$$

Where $B, n, m$ - are material constants depending on the test temperature; [omega] ${ }_{A}^{c}$ - is damageability of material for viscous deformation after energy fracture model; $A_{n p}^{c}$ - specific fracture work for viscous flow of material; $\dot{\omega}_{A}^{c}=d \omega_{A}^{c} / d t ;[\mathrm{ksi}]_{e}^{c}$ and [sigma $]_{e}$ - are equivalent velocities of straining and stress; [sigma $]_{e 0}$ - is equivalent stress dividing the viscous and ductile flows of material.

Since the pressure value $p$ is distributed evenly at every moment of deformation over the surface of the shell, its value was found at the apex of the shell dome (point " $c$ ").

By substituting in the first equation of the material state (8) its values of [sigma $]_{e}$ and $[\mathrm{ksi}]_{e}^{c}$, are to be found after formulas (6) and (7), taking account of correlations (3), (4), (5), we obtain

$$
p^{n} d t=\frac{\sigma_{e 0}^{n}\left(1-\omega_{A c}^{c}\right)^{m} 2^{2 n+2}(2+R)^{\frac{n+1}{2}} H^{n+1} h^{n} d H}{3^{\frac{n+1}{2}} B\left(H^{2}+R_{0}^{2}\right)^{n+1}}
$$

Shell thickness $h$ is found after formula (3).

The value of the accumulated damage is found after: 


$$
\dot{\omega}_{A c}^{c}=\frac{p\left(1+\frac{H^{2}}{R_{0}^{2}}\right)^{2}}{h_{0} A_{n p}^{c}} \dot{H}
$$

Where $\dot{H}=d H / d t$.

Destruction time $t_{*}$ is found from [omega] ${ }_{A c}^{c}=1$.

Carried out in a similar manner was the study of stress and strain states of a blank in the apex of the dome shell (point " $c$ ") and at the point of the shell fixation (point "k"), as well as received were basic equations and proportions for solving the set task, with the assumption that material behavior is subject to the equations of the kinetic theory of creeping and damaging under the well-known law of pressure and time dependence $p=p(t)$ and under permanent equivalent velocity of straining in the blank dome $[\mathrm{ksi}]_{e I}$

There has been developed the algorithm for calculation of force and straining parameters of the analyzed technological process and the software.

There have been evaluated the stress and strained states, the kinematic of the material flow, force conditions and the possibility frontier of straining process under investigation as relating to accumulation of microdamages, as depending on the anisotropy of the mechanical properties of the basic material, depending on the law of loading, and on the geometric dimensions of the blank and the product.

Calculation was made for titanium alloys BT6C at $T=860^{\circ} \mathrm{C}$, which behavior is described by the energy theory of creeping and damaging, and for titanium alloy BT14 at $T=950^{\circ} \mathrm{C}$, which behavior is subject to the kinetic theory of creeping and damaging. The mechanical characteristics of these materials under straining in conditions of viscous flow of material are shown in the works $[5,6]$.

The characteristic curves for changing values of gas pressure $p$, relative values of blank thickness in the dome $\bar{h}_{c}=h_{c} / h_{0}$ and at the place of its fixation $\bar{h}_{k}=h_{k} / h_{0}$, dependence of the height of the dome-shaped blank $\bar{H}=H / R_{0}$ on straining time instant $t$ for titanium alloy BT6C $\left(T=860^{\circ} \mathrm{C}\right)$ at a permanent equivalent straining velocity in the blank dome $[\mathrm{ksi}]_{e l}$ are shown in Fig. 2 . The experimental data are shown here with dots.
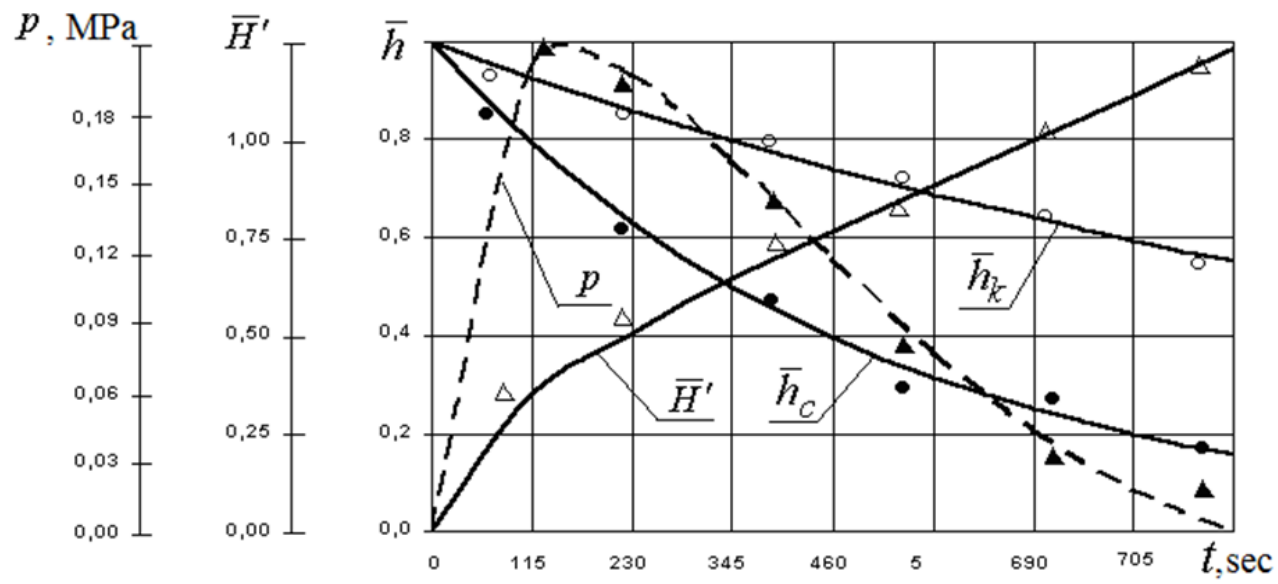

Figure 2. Dependences of $p, \bar{H}$ and $\bar{h}$ changing in the discussed points of a blank from $t$ for titanium alloy BT6C $\left(\bar{R}_{0}=300 ; \xi_{e 1}=0,0021 / c\right)$

It follows from an analysis of the results of calculations and characteristic curves that as straining time $t$ grows to a certain limit, there takes place a steep increase in the blank relative height in dome $\bar{h}_{c}$ and in its place of fixation $\bar{h}_{k}$. Further growth of straining time $t$ results in a smooth change of the analyzed values. At time instant $t$, which is close to the blank destruction, there takes place an abrupt change of the relative values $\bar{H}$, $\bar{h}_{c}$ и $\bar{h}_{k}$. This is caused by an intensive growth of accumulated microdamages at the concluding stage of the process. 
It has been established that the changing of the relative thickness of the blank's dome $\bar{h}_{c}$ takes place in a more intensive manner as versus the changing of its relative thickness at its place of fixation $\bar{h}_{k}$. The difference grows together with straining time $t$ and may reach $50 \%$.

It has been shown that for securing a stable equivalent speed of deformation in the blank dome, the law of changing pressure $p$ during straining time $t$ is of a complex nature. During the initial moment of the shape-changing we witness a steep change in the pressure $p$, since there takes place a substantial change of the radius of the half-sphere $[\mathrm{rho}]_{m}$. Subsequent growth of the straining time $t$ is accompanied by a decrease in the magnitude of the gas pressure $p$.

Comparing theoretical and experimental data on the relative thickness in the blank dome $\bar{h}_{c}$ and at the place of its fixation $\bar{h}_{k}$, as well as on the relative height of the blank $\bar{H}$, shows their satisfactory coincidence (up to $10 \%$ ) $[6]$.

It has been established that the destruction of the blank during the isothermal straining takes place in the dome of the part, where happens the maximum thinning-out of the blank.

Figure 3 shows the changed time of destruction $t_{*}$, the changed relative height $\bar{H}_{*}$, and the changed thickness of the blank dome $\bar{h}_{*}$ at the moment of destruction, as determined by the magnitude of the accumulated microdamages with [omega] ${ }_{\mathrm{A}}^{\mathrm{c}}=1$, -- as having functional connections to the value of the permanent equivalent velocity of straining in the blank dome $[\mathrm{ksi}]_{e l}$. It is shown that increased parameters of the law of loading $a_{p}$, $n_{p}$ and increased magnitude of the value of the permanent equivalent straining velocity in the blank dome $[\mathrm{ksi}]_{e l}$ result in a shorter time of destruction $t_{*}$ and in a smaller relative height $\bar{H}_{*}$, as well as in an increased relative thickness of the blank dome $\bar{h}_{*}$.
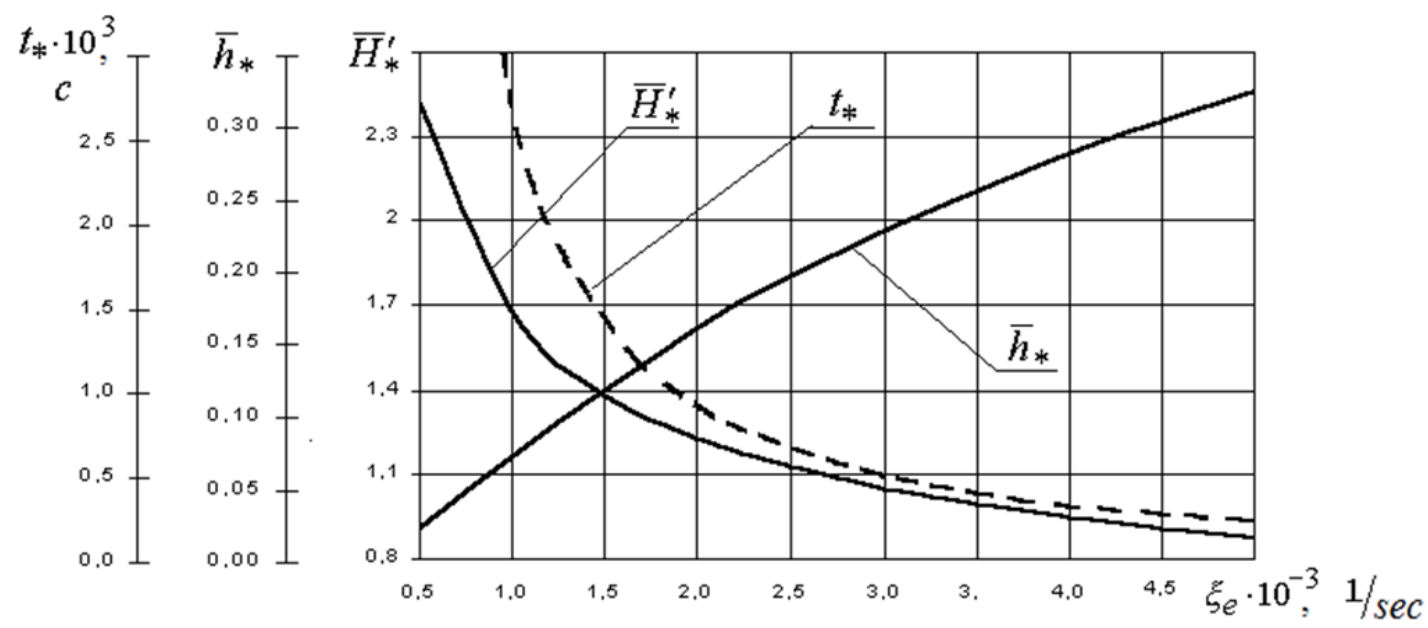

Figure 3. Dependences of changing $t_{*}$ and $\bar{H}_{*}, \bar{h}_{*}$ in the blank dome as relative to [ksi $]_{e}$ for titanium alloy BT6C $\left(\bar{R}_{0}=300\right)$

It is determined that normal anisotropy factor $R$ influences considerably the magnitude of the destruction time and the relative values $\bar{H}_{*}, \bar{h}_{*}$. The calculations have been made at $\bar{R}_{0}=300 ; p_{0}=0,013$ MПa; $a_{p}=4 \cdot 10^{-3} M \Pi a / c^{n_{p}} ; n_{p}=0,6$ (the kinetic theory). As there grows the anisotropy factor $R$, the relative value of $\bar{h}_{*}$ steeply increases, while destruction time $t_{*}$ and the relative blank height fall abruptly. It has been established that the failure of considering the anisotropy of the mechanical properties of the blank when analyzing the process of isothermal changing of the spherical shell shape - makes us err in destruction time $t_{*}$ by about $35 \%$, while in the relative height $\bar{H}_{*}$ and in the thickness of the blank dome $\bar{h}_{*}$ at the moment of destruction - we err by $15 \%$.

Analysis of the calculation results shows that the limit possibilities of shape-changing in the mode of viscous 
flow of material, which conduct is subject to the kinetic theory of creeping and damaging (alloy BT14), do not depend on the conditions of the blank loading. Shown is the substantial dependence of destruction time $t_{*}$ on loading parameters $a_{p}, n_{p}$ and on the value of the permanent equivalent straining velocity [ksi $]_{e l}$. Increasing the loading parameters $a_{p}$ from $0.2 \cdot 10^{-3} M \Pi a / c^{n_{p}}$ to $1.4 \cdot 10^{-3} M \Pi a / c^{n_{p}}$, and those of $n_{p}$ from 0.5 to 0.8 with unchanged other parameters, results in reduction of the destruction time $t_{*}$ by 1.8 times.

There has been shown a substantial influence of the geometric dimensions of the blank upon the destruction time magnitude $t_{*}$. It has been established that an increase in the relative size of the blank radius $\bar{R}_{0}=R_{0} / h_{0}$ from 200 to 800 results in a shorter destruction time by more than 4 times.

\section{Discussion}

Isothermal gas forming of the domed components made of high-strength aluminum and titanium sheet alloys has significant advantages over traditional methods of treatment and is very promising when it is used within the industrial sector. It is less time-consuming and problematic in terms of providing the necessary geometric accuracy due to the presence of residual stresses; it does not cause edge deformation and does not require a large volume of thereof associated mechanical and finishing works on parts fitting to the specified dimensions [11 $20]$.

The suggested mathematic model for the isothermal straining of domed shells made of anisotropic high-strength materials in the mode of creeping, allows us to evaluate the influence of technological parameters, loading conditions, geometry of the working tool, friction conditions on the contact surface of the workpiece and tool on the kinematics of material flow, stress and strain states, force conditions, possibility frontier of forming the process in question, taking into account the anisotropy of mechanical properties, which distinguishes this work out of many other alike studies. (Authors of article offer mathematical model of isothermal deformation of dome-shaped covers by superfluous pressure of gas from anisotropic high-strength materials in a creep mode. The given model allows to estimate kinematics of a current of the material, the intense and deformed conditions of a cover, power modes, the geometrical sizes of made dome-shaped covers and limiting possibilities of deformation. The offered mathematical model can be used as base by working out of technological processes of isothermal deformation of dome-shaped covers).

\section{Conclusions}

Result analysis of the considered process allows drawing the following conclusions:

On the basis of the developed mathematical model the analysis of isothermal deformation of dome-shaped covers with a view of an estimation of kinematics of a current of the material strained and deformed conditions, power modes, the geometrical sizes of covers and limiting possibilities of deformation, in which result has been carried out:

- We have established the influence of technological parameters, the loading conditions, tools geometry, conditions of friction on the contact surfaces of the blank and the tool as affecting the kinematics of the material flow, the stress and strain states, force conditions, the possibility frontier in forming the operations of isothermal straining of dome shells made out of highly strong anisotropic materials.

- It has been shown that for the purpose of providing for permanent equivalent straining velocities in the blank dome, the law of pressure change during straining has a complicated character. It has been determined that changing the relative thickness of the blank dome happens in a more intensive manner by comparison to changing the relative thickness at the main points. As the straining time is increased, the difference may grow to reach $50 \%$.

- It has been established that in the process of isothermal straining of domed blanks, the destruction of the blank occurs in the dome of the blank where there happens a maximal thinning-out of the blank. Increase of the parameters of loading and equivalent straining velocity results in reduction of the relative limit height of the blank and of the destruction time for materials, which conduct is described by the energy theory of creeping and damaging. The possibility frontier of shape-forming during isothermal straining of anisotropic materials, which behavior is described by the energy theory of creeping and damaging, do not depend on the blank loading conditions.

- It has been established that lack of consideration for anisotropy of the blank mechanical properties when analyzing the process of isothermal straining of dome-shaped shells, gives us an error in evaluating the destruction time of about $45 \%$, and of $30 \%$ for the relative height and thickness in the blank dome at the moment of destruction. 


\section{Acknowledgement}

This work has been performed within the frameworks of the basic part of the State Task \#2014/227 for performing research and development works of the Ministry of Education and Science of the Russian Federation for the years 2014-2020 and of the RFFI grant \# 14-08-00066 a.

\section{References}

Abbasia, M., Saeed, A. A., \& Naderi, M. (2012). The effect of strain rate and deformation temperature on the characteristics of isothermally hot compressed boron-alloyed steel. Materials Science and Engineering: A. 538, 356-363. http://dx.doi.org/10.1016/j.msea.2012.01.060

Alwin, S., Volker, U., Christoph, E., Rainer, K., Alfred, K., Monteroe, M. C., Roland, R., Wolfgang, S., Domenico, S., \& Dominique, V. (2008). Opportunities and challenges of spray forming high-alloyed steels. Materials Science and Engineering: A. 477(1-2), 69-79. http://dx.doi.org/10.1016/j.msea.2007.08.082

Chana, K. C., Wanga, G. F., Wanga, C. L., \& Zhang, K. F. (2005). Low temperature superplastic gas pressure forming of electrodeposited Ni/SiCp nanocomposites. Materials Science and Engineering: A. 404(1-2), 108-116. http://dx.doi.org/10.1016/j.msea.2005.05.042

Chunga, S. W., Higashia, K., \& Kim, W. J. (2004). Superplastic gas pressure forming of fine-grained AZ61 magnesium alloy sheet. Materials Science and Engineering: A. 372(1-2), 15-20. http://dx.doi.org/10.1016/j.msea.2003.08.125

DONG, W. P., \& Fea, J. C. (2008). Simulation of 4A11 piston skirt isothermal forging process. Transactions of Nonferrous Metals Society of China, 18(5), 1196-1200. http://dx.doi.org/10.1016/S1003-6326(08)60204-6

Eva-Lis Odenbergera et al. (2008). Thermo-mechanical material response and hot sheet metal forming of Ti-6242. Materials Science and Engineering: A. 489(1-2), 158-168. http://dx.doi.org/10.1007/s12289-012-1094-7

F Grechnikov, F. V. (1998). Deformation of Anisotropic Materials. M. Mashinostroyenie, p. 446.

Fuxiaoa, Y., zhong, C. J., Ranganathanb, S., \& Dwarakadasab, E. S. (2010). Fundamental differences between spray forming and other semisolid processes. Materials Science and Engineering: A., 304-306, 621-626. http://dx.doi.org/10.1016/S0921-5093(00)01547-1

Golenkov, V. A., Yakovlev, S. P., Golovin, S. A., Yakovlev, S. S., \& Kukhar, V. D. (2009). Theory of Metal Processing with Pressure. University text-book. M, p. 442.

Li, L. A., \& Zhang, X. M. (2011). Hot compression deformation behavior and processing parameters of a cast $\mathrm{Mg}-\mathrm{Gd}-\mathrm{Y}-\mathrm{Zr}$ alloy. Materials Science and Engineering: A., 528(3), 1396-1401. http://dx.doi.org/10.1016/j.msea.2014.07.025

Michael, J., O’Briena, F. von, Bremenb, H., Minoru, F., Zenji, H., \& Terence, G. L. (2007). A finite element analysis of the superplastic forming of an aluminum alloy processed by ECAP. Materials Science and Engineering: A., 456(1-2), 236-242. http://dx.doi.org/ 10.1016/j.msea.2006.11.116

Naderia, M., Durrenbergerb, L., Molinarib, A., \& Blecka, W. (2008). Constitutive relationships for 22MnB5 boron steel deformed isothermally at high temperatures. Materials Science and Engineering: A., 478(1-2), 130-139. http://dx.doi.org/10.1016/j.msea.2007.05.094

Puertas, I., Luis-Pérez, C. J., Salcedo, D., León, J., Luri, R., \& Fuertes, J. P. (2013). Isothermal Upset Forging of AA5083 after Severe Plastic Deformation by ECAE. Procedia CIRP., 12, 288-293. http://dx.doi.org/10.1016/j.matdes.2013.05.089

Rusz, S., Sinczak, J., \& Lapkowski, W. (1997). Isothermal plastic forming of high-carbon steel. Materials Science and Engineering: A., 234-236(30), 430-433.

Sinczak, J., Lapkowski, W., \& Rusz, S. (1997). Isothermal plastic forming of high melting temperature alloys. $\begin{array}{lllll}\text { Journal of Materials } & \text { Processing }\end{array}$ http://dx.doi.org/10.1016/S0924-0136(97)00206-9

Yakovlev, S. P., Chudin, V. N., Sobolev, Y. A., Yakovlev, S. S., Tregubov, V. I., \& Larin, S. N. (2009). Isothermal Pneumatic Moulding of Anisotropic High-Strength Sheet Materials. M. Mashinostroyenie, p. 352.

Yakovlev, S. P., Chudin, V. N., Yakovlev, S. S., \& Sobolev, Y. A. (2004). Isothermal Straining of High-Strength Anisotropic Materials. M. Mashinostroyenie, p. 427.

Yakovlev, S. P., Yakovlev, S. S., \& Andreichenko, V. A. (1997). Processing Anisotropic Materials with Pressure. 
Kishinev, Quant, pp: 332.

Yakovlev, S. S., Kukhar, V. D. \& Tregubov, V. I. (2012). Theory and Technology of Stamping Anisotropic Materials. M. Mashinostroyenie, p. 400.

Zhao, W. J., Cao, F. Y., Gu, X. L., Ning, Z. L., Han, Y., \& Sun, J. Y. (2013). Isothermal straining of spray formed $\mathrm{Al}-\mathrm{Zn}-\mathrm{Mg}-\mathrm{Cu}$ alloy. Mechanics of Materials, 56, 95-105. http://dx.doi.org/10.4028/www.scientific.net/MSF.788.565.

\section{Copyrights}

Copyright for this article is retained by the author(s), with first publication rights granted to the journal.

This is an open-access article distributed under the terms and conditions of the Creative Commons Attribution license (http://creativecommons.org/licenses/by/3.0/). 